\title{
Peningkatan Produksi dan Kekuatan Mekanik Batu Bata Press Menggunakan Mesin Cetak Kapasitas 1000 Buah/Jam pada Usaha Keluarga di Desa Kalipucang Kulon
}

\author{
Improving the Production and Mechanical Power of Pressed Bricks using a \\ Printing Machine with the Capacity of 1000 pieces / hour at a Family Business in \\ Kalipucang Kulon Village
}

Solechan, Aris Kiswanto

Fakultas Teknik, Universitas Muhammadiyah Semarang (Unimus), Semarang solechan1981@gmail.com, ariskiswanto99@gmail.com

Riwayat Artikel: Dikirim 28 September 2018; Diterima 28 November 2018; Diterbitkan 30 November 2018

\begin{abstract}
Abstrak
Kota Jepara salah satu kota dimana terdapat peluang usaha untuk memenuhi kebutuhan batubata. Sentra batu bata salah satunya berada di desa Kalipucang Kulon kecamatan Welahan. Dari kekuatan mekanik batu bata masih di bawah standar, densitas rendah, porositas tinggi dan warna merah. Batu bata mengandung pasir besi dan jenis tanah lempung merah. Usaha pembuatan batu bata di desa Kalipucang Kulon sebanyak 54 buah yang terdaftar di kantor Kelurahan tahun 2015. Banyak terjadi permasalahan di mitra UK batu bata Kalipucang Kulon, antara lain, pembuatan batu bata konvesnsional dan ukuran batu bata tidak standar SNI. Aspek pemasaran masih menunggu pembeli, manajeman usaha bersifat kekeluargaan dan minimnya strategi pemasaran,modal terbatas, dan kurangnya informasi mengakses pinjaman modal. Tujuan pengabdian pada masyarakat Program Kemitraan Masyarakat (PKM) yaitu pembuatan mesin batu bata untuk meningkatkan produksi, pembuatan dan pemeliharaan website e-commerce untuk jual produk batu bata, manajemen usaha, strategi pemasaran, member informasi dan pendampingan mendapatkan modal usaha. Metode yang dipakai adalah Workshop pembuatan dan pengoperasian mesin batu bata press sesuai standar SNI, pelatihan pembuatan dan pemeliharaan website e-commerce, memberikan pelatihan kewirausahaan, strategi pemasaran produk, member informasi dan pendampingan untuk mendapatkan modal usaha,dan cara mengakses bantuan dana. Hasilnya dengan penerapan mesin batu bata press manpu meningkatkan $880 \%$ dibandingkan dengan manual tenaga manusia. Kekuatan mekanik batu bata merah paling optimal dimiliki oleh komposisi campuran dengan kode B3 dengan kekuatan tekan $41.712 \mathrm{Kg} / \mathrm{cm} 2$ dan densitas 25,87 kg/m3. Peningkatan produksi dengan sifat mekanik batu bata press mampu meningkatkan pendapatan usaha keluarga dan kualitas batu bata.
\end{abstract}

Kata kunci: Kalipucang, batu bata, mesin, ektruder, densitas

\begin{abstract}
Jepara is one of town where there is a business opportunity to meet the need of bricks. The brick industry center is located in Kalipucang Kulon Village, Welahan Subdistrict. Seen from the mechanical power, the bricks are still below the standard, with low density, bigh porosity, and red in color. Bricks contain iron sand and are made of red clay soil. There are 54 registered business entities of bricks in Kalipucang Kulon Village in 2015. There have been a lot of problems faced by the partner of the community service program in Kalipucang Kulon Village, such as the brick making is still conventional and the dimensions are not based on the (Indonesian National Standard or SNI. The marketing aspect is that they still wait for buyers. Besides, the management is family-based, the marketing strategies are still minimal, the capical is limited, and there is a lack of information about how to access capital loan. The Community Partnership Program was aimed at creating a brick making machine that would increase the production rate, creating and maintaining e-commerce website to sell the bricks, teaching about business management and marketing strategies, and giving information and assistances to get venture capital. Method applies was by giving a workshop on creating and operating press brick machine based on the SNI, training on creating and maintaining ecommerce website, training on entrepreneurship, and product marketing strategies, and giving information and assistances to get venture capital and how to access capital loan. The result showed that by using the press brick machine, the production had been increasing up to $880 \%$ compared to when making manually. The most optimal mechanical power of red bricks was when the bricks were made of the composition of mixture coded B3 with compressive strength of $41.712 \mathrm{Kg} / \mathrm{cm} 2$ and density of 25,87 $\mathrm{kg} / \mathrm{m} 3$. The production increase using press brick machine has improve the family's revenue as well as the bricks' quality itself.
\end{abstract}

Keywords: Kalipucang, bricks, machine, extruder, density 


\section{PENDAHULUAN}

\section{Analisis Situasi}

Pesatnya pembangunan di sektor perumahan dan properti menjadikan kebutuhan batu bata semakin meningkat, ini membuka peluang usaha pengadaan material bangunan untuk mendukung pembangunan sektor tersebut (www.jambiindependent.co.id). Kota Jepara salah satu kota yang melihat peluang usaha tersebut untuk memenuhi kebutuhan batu bata, salah satunya desa Kalipucang Kulon kecamatan Welahan Kabupaten Jepara
Provinsi Jawa tengah. Dari kekuatan mekanik batu bata masih di bawah standar, densitas rendah, porositas tinggi dan warna merah bagaimana diperlihatkan pada Gambar 1. Kekuatan tekan batu bata hanya $21.33 \mathrm{Kg} / \mathrm{cm} 2$ dan densitas $14,41 \mathrm{~kg} / \mathrm{m} 3$, ini masih di bawah standar Industri Indonesia SII-0021-1978. UK Bata Jepara dan UK Batu Bata Merah merupakan pengusaha batu bata di desa Kalipucang Kulon dan menjadi mitra pengabdian masyarakat PKM.

Gambar 1:

Batu Bata Desa Kalipucang Kulon

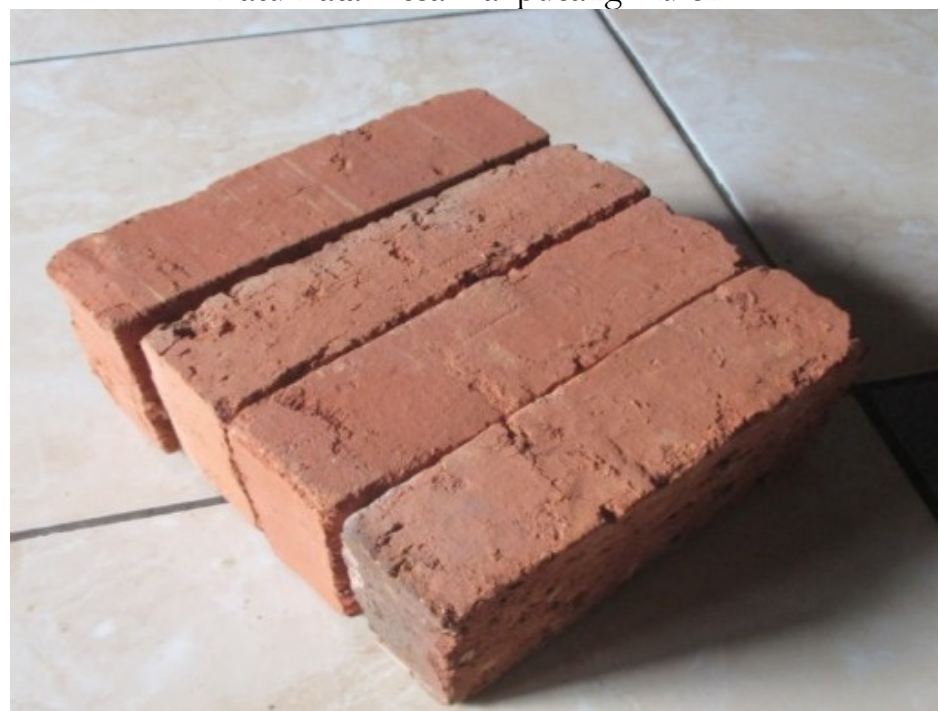

Sumber: Dokumentasi lapangan, 2018

Gambar 2:

Proses pembuatan batu bata secara manual

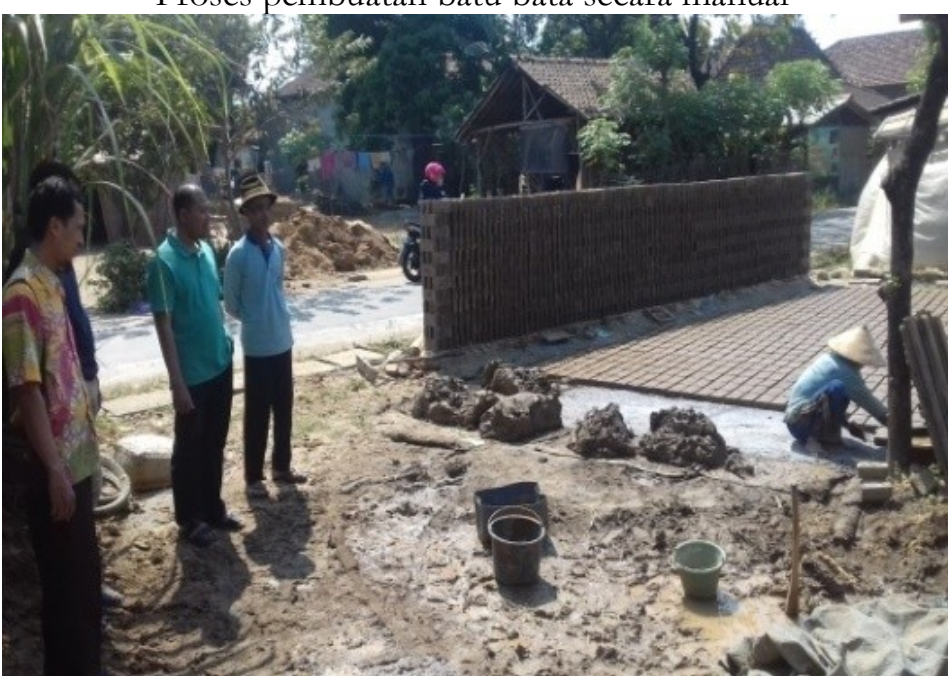

Sumber: Dokumentasi lapangan, 2018 
Kapasitas produksi batu bata 4.500 bata/hari. Setiap percetakan bata membutuhkan 2 orang tenaga kerja. 1 orang mencetak dan 1 orang untuk mengirim material tanah. Model pencetakan batu bata masih konvensional dengan alat-alat sederhana yang diperlihatkan pada Gambar 2. UK Bata Jepara Merah memiliki 3 tim pembuat batubata. 1 tim mengasilkan kurang lebih $1.250 \mathrm{bata} / \mathrm{hari}$ dengan waktu kerja 6 jam tiap hari. Model pembayaran karyawan borongan, 1 batu bata mentah belum dibakar dihargai Rp. 150. Sehingga 1 tim mampu mendapatkan gaji Rp.187.500. Pembagian gaji untuk pencetak Rp. 110.000 untuk pengirim material Rp. 77.500. Gaji karyawan perbulan untuk pencetak mengantongi uang Rp. 2.640.000 dan pengirim material $\mathrm{Rp}$ 1.840.000. Kualitas produksi cetak batu bata konvensional banyak berlubang, kasar, tidak rapi, patah, dan proses lama. Ukuran batu bata yang dihasilkan kedua mitra yaitu 185 x 100 x 48 mm, ukuran ini tidak sesuai dengan Standar Nasional Indonesia (SNI). Ukuran batu bata SNI 15-2094-2000 yaitu 210 x 110 x $50 \mathrm{~mm}$. Dari permasalahan di atas, perlu dilakukan untuk perbaikan kualitas batu bata, menstandarkan produks sesuai SNI dan meningkatkan produksi batu bata di UR batu bata di desa Kalipucang Kulon.

\section{Tujuan Kegiatan}

a. Memperbaiki kualitas dari segi kekuatan mekanik batu bata sesuai standar Industri Indonesia SII-00211978.

b. Menggantikan produksi batu bata secara manual dengan mesin semi otomatis untuk meningkatkan produksi batu bata dan menyesuaikan ukuran sesusai SNI.

\section{METODE}

Metode kegiatan pengabdian masyarakat dan tujuan yang dicapai pada program IbM ditampilkan pada Tabel 1.

Tabel 1:

Rencana kegiatan dan tujuan yang akan dicapai

\begin{tabular}{|l|l|l|}
\hline No & \multicolumn{1}{|c|}{ Rencana Kegiatan } & \multicolumn{1}{c|}{ Tujuan Yang akan dicapai } \\
\hline 1 & $\begin{array}{l}\text { Workshop pelatihan pengoperasian mesin } \\
\text { batu bata press sesuai ukuran SNI }\end{array}$ & $\begin{array}{l}\text { Peserta pelatihan mampu } \\
\text { mengoperasikan mesin batu bata press } \\
\text { sesuai SOP dan mampu menyelesaikan } \\
\text { trouble shooting saat ada kerusakan. }\end{array}$ \\
\hline 2 & $\begin{array}{l}\text { Mencoba membuat komposisi campuran } \\
\text { tanah liat untuk bata bata press dan menguji } \\
\text { kekuatan mekanik dengan uji tekuk dan } \\
\text { densitas. }\end{array}$ & $\begin{array}{l}\text { Menentukan komposisi campuran tanah } \\
\text { liat yang sesuai dalam penerapan mesin } \\
\text { batu bata press dan mencari kekuatan } \\
\text { mekanik yang paling optimal }\end{array}$ \\
\hline
\end{tabular}

\author{
Mesin Batu Bata Press Kapasitas 1000 \\ pcs/jam \\ a. Dimensi $365 \times 50 \times 65 \mathrm{~cm}$, bentuk fisik \\ ditampilkan pada Gambar 2. \\ b. Kapasitas 1000 bata/jam. \\ c. Power: Diesel 24 PK, 2200 RPM merk \\ Kobai. \\ d. Berat $580 \mathrm{~kg}$
}

e. Reducer: Gardan Hi-Ice

f. Rangka: Profil U tipe UNP 8 SNI

g. Pulley set: B238 MATL Baja Tuang

h. Roll Silender: $\varnothing 22 ”$ MATL STEEL.

i. Gear: T30 MATL Baja Tuang

j. Sprocket RS 80

k. Spiral: MATL Baja Tuang ASME B16.

1. Hasil potong 3 pcs 
Gambar 3:

Mesin batu bata press kapasitas 1000 pcs/jam

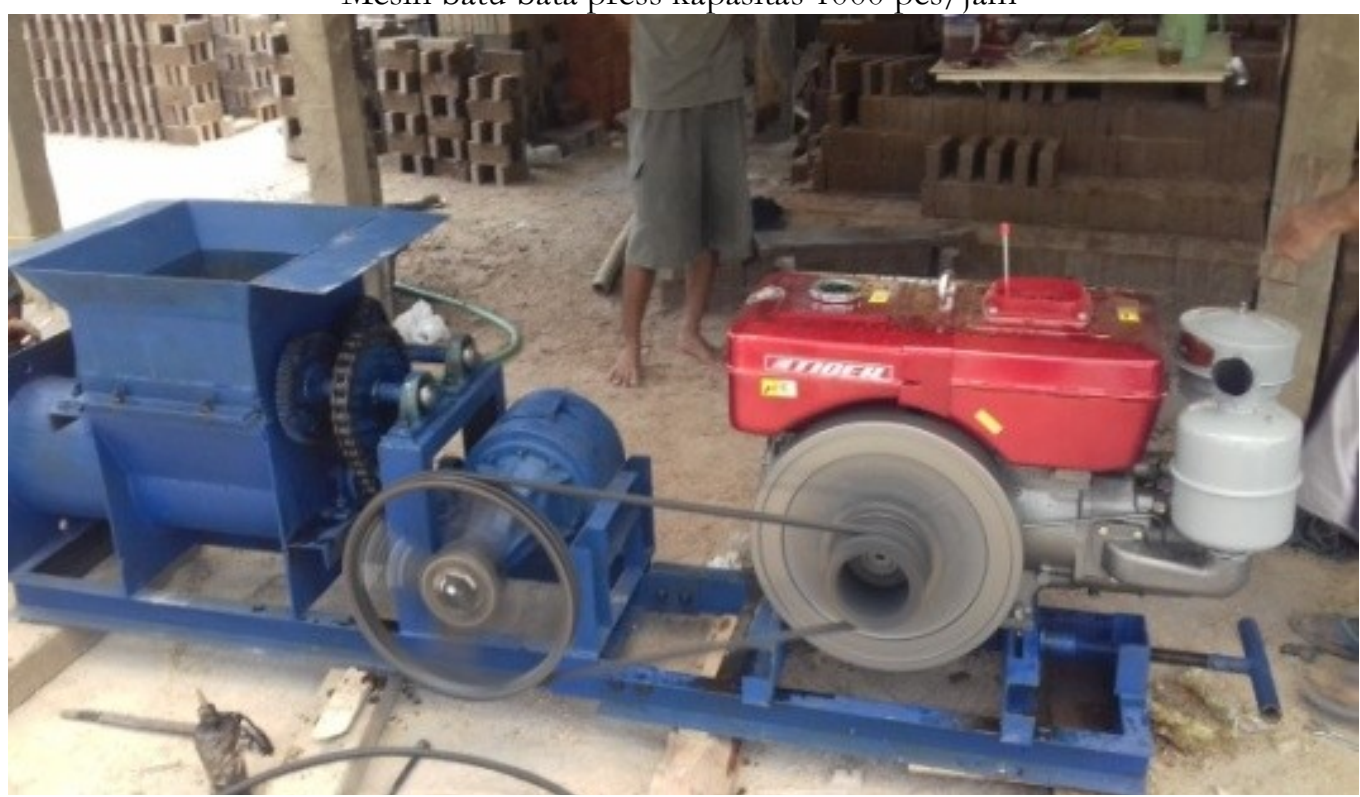

\section{Komposisi Campuran Tanah Liat untuk Batu Bata Press}

Komposisi campuran antara ketiga bahan disesuaikan dengan putaran (rpm) mesin diesel supaya memiliki kekuatan mekanik maksimal. Proses pencampuran bahanbahan menggunakan proses manual dengan tenaga manusia dan alat bantu cangkul, sekop, dan selang air. Komposisi untuk campuran tanah liat, sekam padi (brambut), dan air dengan perbandingan 85:10:5, 90:5:5, dan 92:3:5. Komposisi dapat menentukan kekuatan tekan, kekuatan bending, dan densitas batu bata. Proses pengadukan atau mixer dari material tersebut, membutuhkan waktu 1-2 jam. Hasilnya dibiarkan 1 hari untuk menghilangkan kanduangan air dalam adonan.

\section{Analisa Data}

Metode deskriptif analisis untuk pengambilan data. Proses pengambilan data kekuatan mekanik dari hasil uji tekan dan densitas, sedangkan kapasitas produksi batu bata press per jam dengan mesin diambil dari ketiga komposisi campuran tanah liat.

\section{HASIL DAN PEMBAHASAN}

Hasil kegiatan pengabdian masyarakat program PKM pada Usaha Keluarga pembuatan batu bata di desa Kalipucang Kulon Kecamatan Welahan Kabupaten JeparaProvinsi Jawa Tengah sebagai berikut:

\section{Hasil Uji Tekan dan Densitas Batu Bata}

Pengujian uji tekuk menggunakan mesin Universal Testing Machine (UTM) tipe WDW 100E FLOOR dengan beban $3 \mathrm{KN}$. Pengujian sebanyak 5x (lima) setiap specimen uji. Kondisi batu bata dalam kondisi kering dan sudah dibakar yang diperlihatkan pada Gambar 4. 
Gambar 4:

Spesimen uji tekuk batu bata press

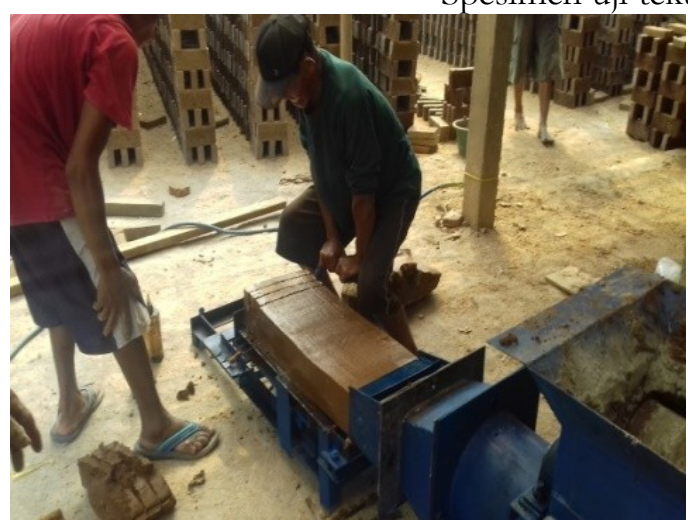

Hasil pengujian batu bata press pada ketiga komposisi campuran untuk uji tekuk. Dimensi spesimen 210 x 110 x 50 $\mathrm{mm}$ dengan kuat tekan batubata menurut standar Industri Indonesia SII-00211978.Tegangan tekan internal yang ditimbulkan oleh gaya tekan diasumsikan tersebar atu didistribusikan merata keseluruhan penampang batu bata menimbulkan intensitas atau tegangan yang sebenarnya (Sukobar, Kuntjoro,

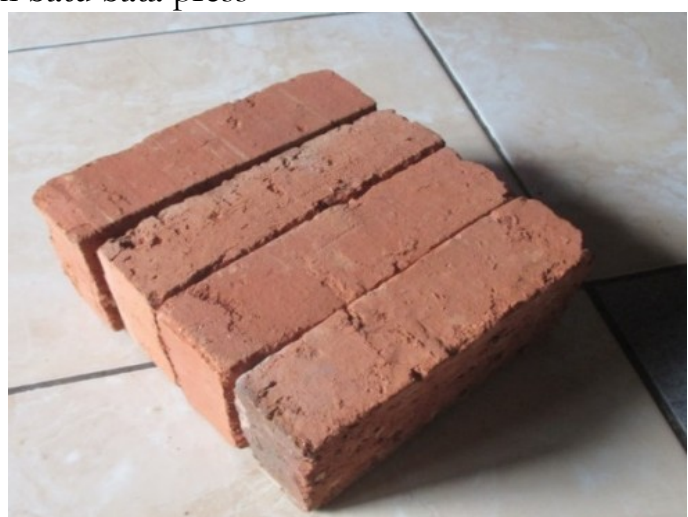

Kusumastuti, \& Sungkono, 2014) Hasil uji tekan untuk batu bata press yang paling baik dimiliki oleh komposisi campuram dengan kode B3 dengan perbandingan 92:3:5 dengan kekuatan tekan 41.712 $\mathrm{Kg} / \mathrm{cm} 2$. Menurunnya persentase kandungan tanah menurunkan kekutan tekan batu bata press bagaimana diperlihatkan pada Gambar 5.

Gambar 5:

Hasil uji tekan batu bata press

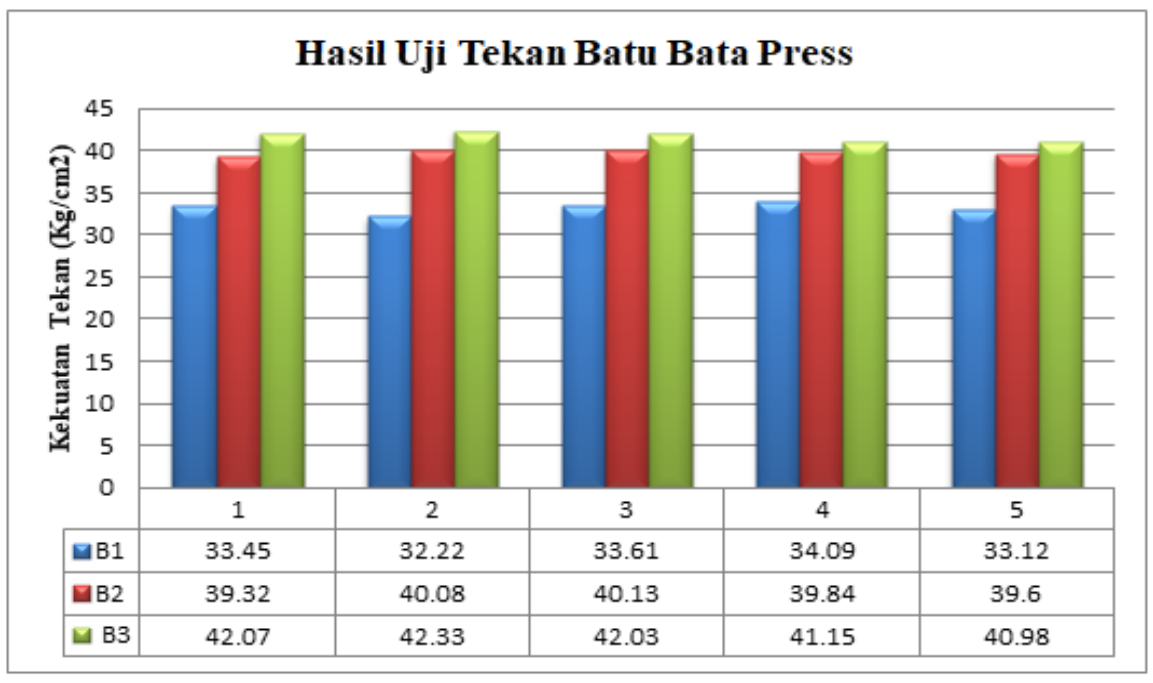

Ini terjadi pada komposisi campuran kode B2 yang mengalami penurunan 1.918 $\mathrm{Kg} / \mathrm{cm} 2$ atau $4.59 \%$. Untuk Kode B1 mengalami penurunan $8.414 \mathrm{Kg} / \mathrm{cm} 2$ atau
$20.17 \%$. Menurunya kekuatan tekan ini diakibatkan berkurangnya berat volume dan densitas batu bata press karena bertambahnya komposisi campuran sekam padi (William D. 
Callister,Jr., 1990). Sekam padi saat pembakaran batu bata press terbakar menjadi abu, sehingga terbentuk pori-pori dan menurunkan densitas. Hasil pengujian densitas atau massa jenis dari masing-masing spesimen batu bata press dengan variasi komposisi campuran diperlihatkan pada Gambar 5. Komposisi campuran kode B3 memiliki densitas paling tinggi yaitu 25,87 kg/m3, sedangkan komposisi campuran kode B2 yaitu $24,02 \mathrm{~kg} / \mathrm{m} 3$ mengalami penurunan densitas sebesar $1.87 \mathrm{~kg} / \mathrm{m} 3$ atau 7,15\%. Bertambahnya komposisi campuran sekam padi menurunkan densitas, ini dialami komposisi campuran kode B1 memiliki densitas paling rendah yaitu 20.11 $\mathrm{kg} / \mathrm{m} 3$ atau mengalami penurunan $22.26 \%$.

Gambar 6:

Hasil densitas batu bata press

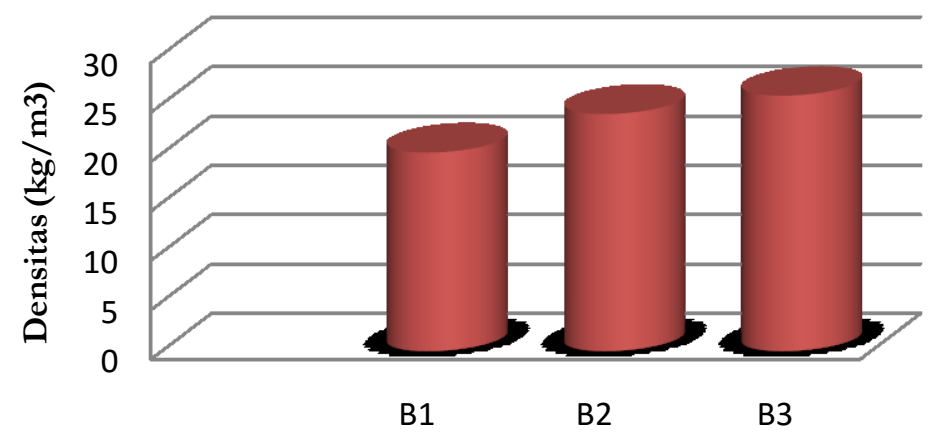

Komposisi Campuran Batu Bata Press

\section{Kapasitas Produksi Mesin Batu Press}

Kapasitas produksi mesin batu bata press mampu mencetak 1.000 buah/jam. Pada percobaan ini menggunakan komposisi campuran bahan batu bata dengan kode B1, B2, dan B3. Sedangkan manual dengan tenaga manusia kode $K$ per jam mampu menghasilkan 103 buah. Untuk mengetahui kapasitas produksi mesin batu pressdengan waktu percobaan selama 5 menit untuk mempercepat pengambilan hasil uji. Waktu 5 menit dikalikan 12 kali menjadi 60 menit atau 1 jam untuk mendapatkan kapasitas prosuksi buah/jam. Hasil pengujian kapasitas produksi mesin batau bata press untuk semua komposisi campuran bahan batu bata press diperlihatkan pada Gambar 7.

Gambar 7:

Kapasitas produksi mesin batu bata press

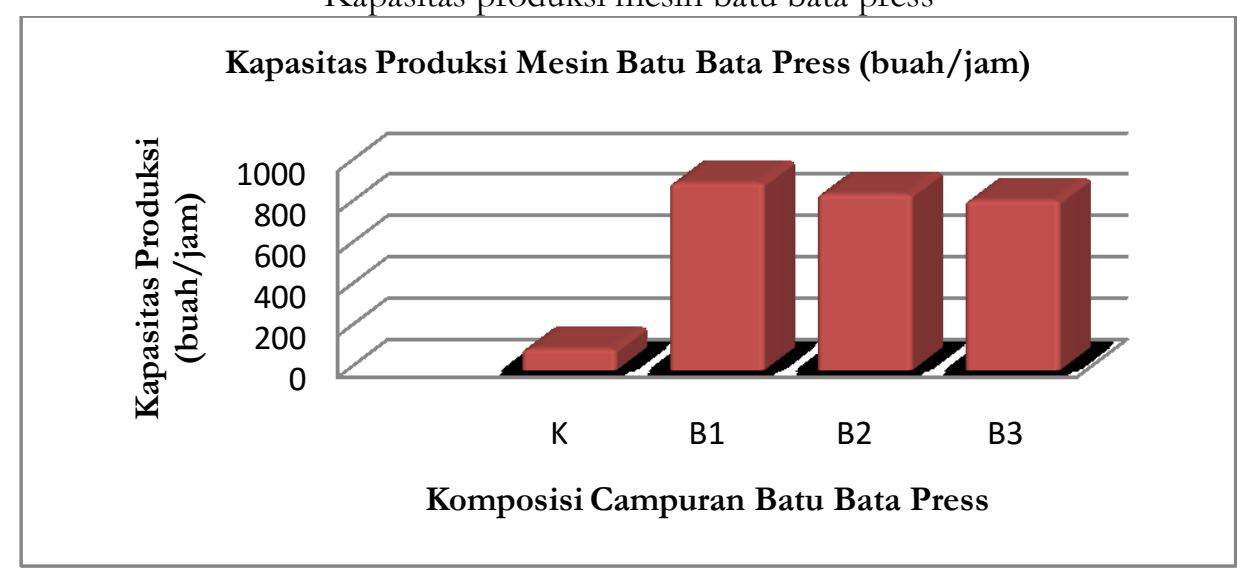


Kapasitas produksi cetak batu bata press paling tinggi pada komposisi campuran B1 dengan komposisi tanah liat $85 \%$, sekam padi $10 \%$, dan air $5 \%$ sebesar 909 buah/jam. Komposisi campuran kode B2 mampu produksi $855 \mathrm{buah} / \mathrm{jam}$ atau mengalami penurunan $54 \mathrm{buah} / \mathrm{jam}$ (5,94\%). Kapasitas produksi cetak paling rendah pada komposisi campuran kode B3 yaitu $824 \mathrm{buah} / \mathrm{jam}$ mengalami penurunan $85 \mathrm{buah} / \mathrm{jam} \quad(9,35 \%)$. Apabila dibandingkan dengan manual atau konvesional mengalami peningkatan $880 \%$. Berrtambahnya komposisi campuran sekam padi mampu meningkatkan produksi cetak batu bata. Sekam padi memiliki permukaan yang halus dan densitas rendah sehingga gaya gesek rendah dan proses keluarnya tanah liat dari mulut cetakan lebih cepat. Permukaan sekam padi yang halus menggurangi gesakan antar muka dengan dinding cetakan dan kecepatan meluncurnya tanah liat lebih cepat dan berbanding lurus dengan kapasitas produksi yang besar (Rusmardi, 2012).

\section{KESIMPULAN}

1. Kekuatan mekanik batu bata press paling optimal dimiliki oleh komposisi campuran dengan kode B3 dengan kekuatan tekan $41.712 \mathrm{Kg} / \mathrm{cm} 2$ dan densitas $25,87 \mathrm{~kg} / \mathrm{m} 3$.

2. Penerapan mesin batu bata press mampu meningkat $880 \%$ dibandingkan dengan manual tenaga manusia.

\section{UCAPAN TERIMA KASIH}

Penulis mengucapkan terima kasih kepada Kementerian Riset Teknologi Dan Pendidikan Tinggi (Kemenristekdikti) Republik Indonesia yang telah memberikan dana untuk pengabmas program PKM tahun anggaran 2017-2018.

\section{DAFTAR PUSTAKA}

BPS Desa Kalipucang Kulon. (2015). Desa Kalipucang Kulon Dalam Angka 2015. Fransiskus. (2010). Usaha Batu Bata. Diambil dari www.jambiindependent.co.id

Rusmardi, R. (2012). Analisis Percobaan Gesekan (Friction) untuk Pengembangan Teknologi Pengereman pada Kendaraan Bermotor. POLI REKAYASA, 3(2), 81-89.

Sukobar, S., Kuntjoro, K., Kusumastuti, K., \& Sungkono, S. (2014). Kesetaraan Kuat Tekan Batu Bata (Press) Asal Bangsal Mojosari Kabupaten Mojokerto Terhadap Kuat Tekan Spesi Campuran Semen, Kapur, dan Pasir untuk Pasangan Bata. Jurnal Aplikasi Teknik Sipil, 12(2), 13-20.

SNI 15-2094-2000., Syarat-syarat batu bata., hal 23-24. Jakarta.

William D. Callister ,Jr. (1990). Materials Science And Engineering An Introduction. Second Ed.. New York

www.oscommerce.com, diakses pada tanggal 6 Agustus 2014. 